\title{
Common causes of blindness and visual handicap in the west of Scotland
}

\author{
ISSAM M. GHAFOUR, ' DONALD ALLAN, ${ }^{2}$ AND WALlACE S. FOULDS' \\ From the 'Tennent Institute of Ophthalmology, Glasgow, and the ${ }^{2}$ West of Scotland Health Boards, \\ Department of Clinical Physics and Bio-Engineering, Glasgow
}

SUMMARY An analysis of blind registration forms was made to determine the commonest causes of blindness in the west of Scotland. It was found that the leading causes of blindness in order of frequency of incidence were senile macular degeneration, glaucoma, cataract, diabetic retinopathy, and myopic degeneration. Diabetic retinopathy was the leading cause of blindness among persons of working age.

In the UK all persons with legal blindness-that is, those whose vision is too poor to allow work for which eyesight is necessary (in general a corrected visual acuity of less than $3 / 60$ in the better eye or a visual field of less than $10^{\circ}$ )- may be placed on the blind register by having a certificate of blind registration completed by an ophthalmologist (Form BP1 in Scotland and Form BD8 in England). Persons who have a permanent and significant visual handicap as the result of a congenital defect, an injury, or disease (in general a vision of $3 / 60-6 / 60$ ) may be similarly registered as partially sighted.

Analyses of the predominant causes of blindness have been performed for a number of countries, including England and Wales, ${ }^{1}$ Sweden, ${ }^{2}$ and the United States of America. ${ }^{3}$ In this paper a comparison is made between the causes of blindness in the west of Scotland and those reported from other parts of the world.

\section{Materials and methods}

Forms BP1 for the year ended 31 December 1980 and returned to the Society for the Blind in Glasgow and the West of Scotland were studied. These forms relate to people resident in Strathclyde Region. This is the area covered by the area health boards of Greater Glasgow, Argyll and Clyde, Ayrshire and Arran, and Lanarkshire.

Seven hundred and seventy two visually handicapped people were registered with the society during the year 1980. Of this number 125 forms, $16 \%$ of the

Correspondence to Professor W. S. Foulds. Tennent Institute of Ophthalmology, Glasgow G11 6NT. total, had to be excluded from further analysis because of lack of essential information. These rejected forms contained nothing other than the name of the ophthalmologist and person being registered. We believe that the exclusions do not invalidate our findings; all the rejected forms came from one ophthalmologist in an area with no apparent abnormal incidence of causes of blindness, as assessed from a study of forms returned by other ophthalmologists working in the same area.

Patients with visual loss from cerebrovascular accident where visual loss was a homonymous field defect were classed as partially sighted for the purpose of the study. In some instances ophthalmologists registered such patients as legally blind and in others as partially sighted. Because these patients in general retained a useful field of vision, it was thought that the partially sighted category was the more appropriate.

Computer input was prepared from the remaining 647 fully completed forms, summarising the most important data on the Forms BP1. The facts considered were the age and sex of the person, the visual acuity and the visual field for each eye, and the primary cause of blindness for each eye. Both the age of the person at the time of examination for registration and that at which the visual handicap developed were noted. The data were analysed on the Edinburgh Regional Computer Centre ICL 2980 by means of some of the standard data handling facilities of the MINITAB program package.

For the purpose of analysis patients were divided into the following age groups $0-4,5-19,20-44$, $45-64,65-74,75-84$, and $85+$. This age grouping has been used in a previous study. ${ }^{3}$ 


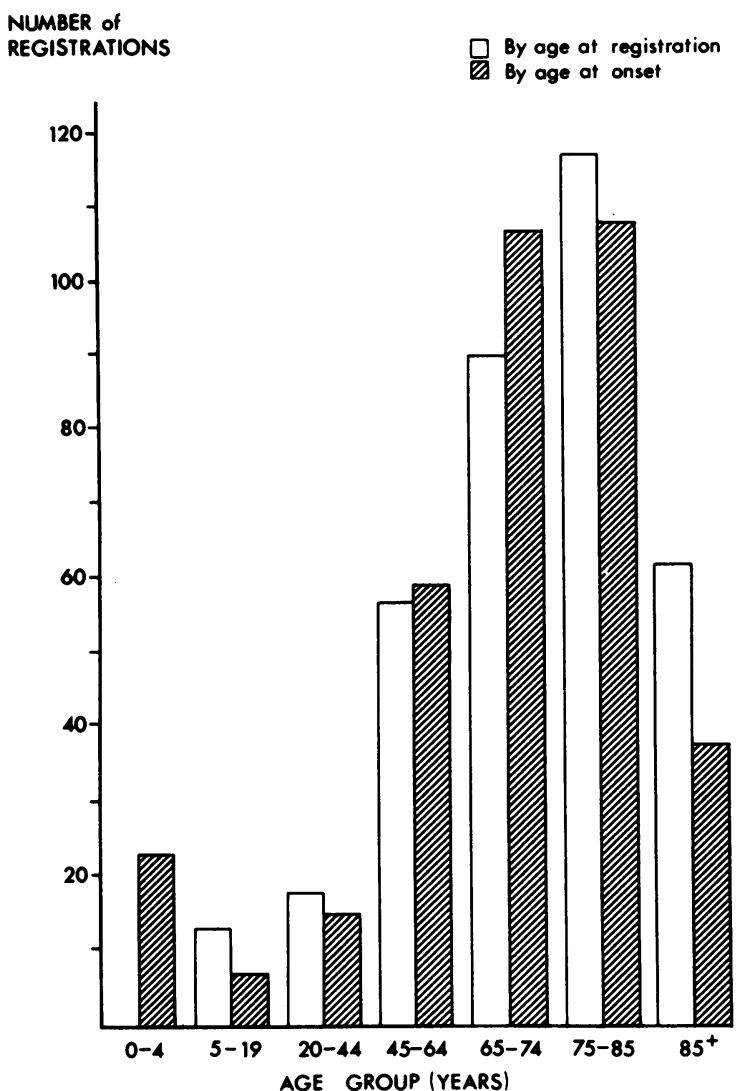

Fig. 1 Numbers of eyes registered blind classified by age: $\square$ by age of registration; $\square \pi$ by age at onset of blindness.

\section{Results}

The 647 completed Forms BP1 were in respect of 253 males and 394 females. Of these, 138 males and 219 females were legally blind (total 357 or $55 \%$ ). The male-to-female ratio was $2: 3$ both for the total registration and for the legally blind. The male-to-female ratio in the population as a whole is $1: 1 \cdot 1$ in the west of Scotland. ${ }^{4}$

Fig. 1 depicts the age distribution of the legally blind. Because registration usually takes place some time after the onset of blindness, the distribution for 'age at registration' tended to be shifted to an older age than that for 'age at onset.' In fact the median time between the onset of the visual defect and registration was one year. Some $64 \%$ of registrations were made within 2 years of the onset of blindness, but owing to the long tail of the distribution times a

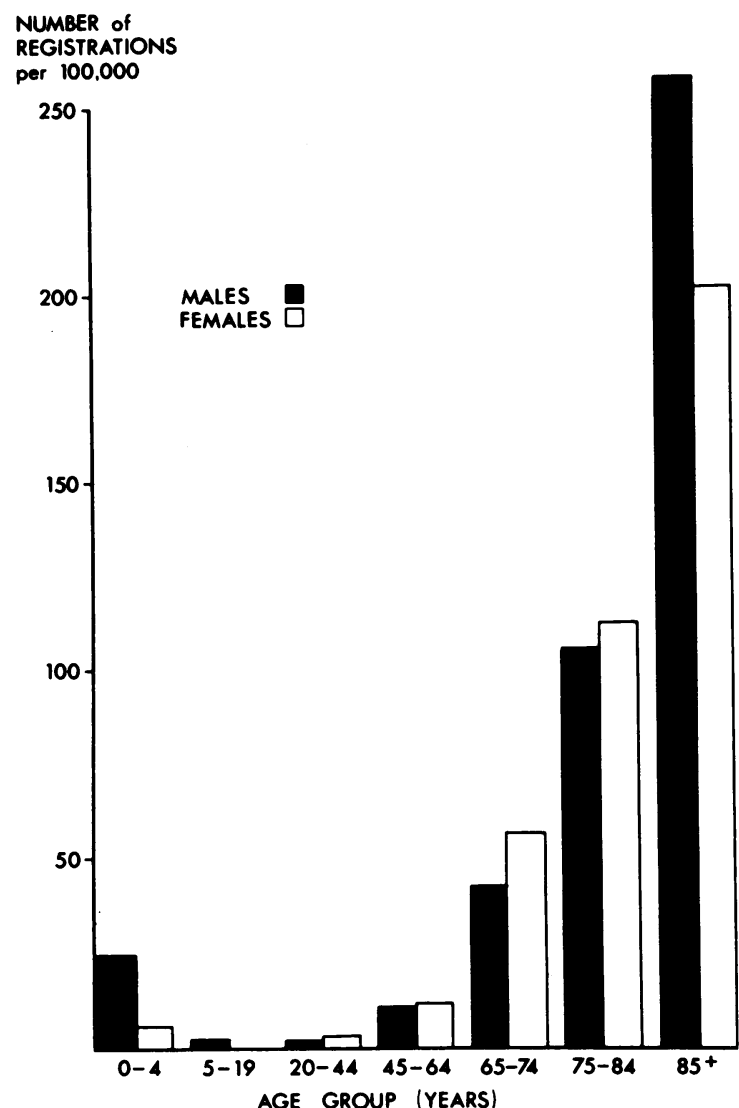

Fig. 2 Numbers of eyes registered blind per 100000 population: $\square$ for males; $\square$ for females.

few registrations were made more than 20 years after the person became blind.

The peak incidence of onset of blindness occurred in the 75-84 year age group, but there were almost as many whose onset of visual loss was between 65 and 74 years of age. $30 \%$ of all registrations fell within each of these 2 age groups. The incidence of registration reached a peak in the 75-84 year group with 33\% of all legally blind registrations.

The data have been corrected for age on an actuarial basis by using the mid-1980 population estimates for Strathclyde Region. ${ }^{4}$ The results are shown in Fig. 2, and it was found that, as expected, blindness became increasingly common with advancing age, and the incidence rose sharply around 60 years of age. The corrected incidences are comparable for males and females, given the limits on interpretation set by the small numbers of registra- 
Table 1 Leading causes of legal blindness for all ages and individual age groups, west of Scotland, 1980

\begin{tabular}{|c|c|c|c|c|c|c|c|}
\hline & & $\begin{array}{l}\text { No. of } \\
\text { eyes }\end{array}$ & $\%$ & & & $\begin{array}{l}\text { No. of } \\
\text { eyes }\end{array}$ & $\%$ \\
\hline & Overall total & & & & Age group 45-64 & & \\
\hline 1. & Sen. mac. deg & 213 & $29 \cdot 8$ & 1. & Diab. ret. & 22 & $18 \cdot 6$ \\
\hline 2. & Glaucoma & 104 & $14 \cdot 6$ & 2. & Sen. mac. deg. & 17 & $14 \cdot 4$ \\
\hline 3. & Cataract & 74 & $10 \cdot 4$ & 3. & Glaucoma & 15 & $12 \cdot 7$ \\
\hline 4. & Diab. ret. & 61 & $8 \cdot 5$ & 4. & Myopic deg. & 10 & $8 \cdot 5$ \\
\hline 5. & Myopic deg. & 43 & $6 \cdot 0$ & 5. & Optic atrophy & 10 & $8 \cdot 5$ \\
\hline 6. & Optic atrophy & 32 & $4 \cdot 5$ & & All others & 44 & $37 \cdot 3$ \\
\hline \multirow[t]{4}{*}{7.} & Corneal opacity & 20 & $2 \cdot 8$ & & Total & 118 & $100 \cdot 0$ \\
\hline & All others & 167 & $23 \cdot 4$ & & Age group 65-74 & & \\
\hline & Total & 714 & $100 \cdot 0$ & 1. & Sen. mac. deg. & 56 & $26 \cdot 2$ \\
\hline & Under 5 years of age & & & 2. & Glaucoma & 44 & $20 \cdot 5$ \\
\hline 1. & Optic atrophy & 14 & $30 \cdot 3$ & 3. & Cataract & 24 & $11 \cdot 2$ \\
\hline 2. & Corneal and other postnatal infections & 12 & $26 \cdot 1$ & 4. & Diab. ret. & 19 & 8.9 \\
\hline 3. & Prenatal cataract & 8 & $17 \cdot 4$ & 5. & Myopia & 10 & $4 \cdot 7$ \\
\hline 4. & Cong. glaucoma, microphthalmos & 8 & $17 \cdot 4$ & & All others & 61 & $28 \cdot 5$ \\
\hline & Tumour & 2 & $4 \cdot 4$ & & Total & 214 & $100 \cdot 0$ \\
\hline & All others & 2 & $4 \cdot 4$ & & Age group $75-84$ & & \\
\hline & Total & 46 & $100 \cdot 0$ & 1. & Sen. mac. deg. & 103 & $47 \cdot 7$ \\
\hline & Age group 5-19 & & & 2. & Glaucoma & 35 & $16 \cdot 2$ \\
\hline 1. & Ret. pigmentosa & 6 & $42 \cdot 8$ & 3. & Cataract & 19 & $8 \cdot 8$ \\
\hline 2. & Optic atrophy-cong. & 2 & $14 \cdot 3$ & 4. & Diab. ret. & 14 & $6 \cdot 5$ \\
\hline 3. & Myopia & 2 & $14 \cdot 3$ & 5. & Myopic deg. & 10 & $4 \cdot 6$ \\
\hline 4. & Injury & 2 & $14 \cdot 3$ & & All others & 35 & $16 \cdot 2$ \\
\hline \multirow[t]{3}{*}{5.} & Cong. microphthal. toxoplasmosis & 2 & $14 \cdot 3$ & & Total & 216 & $100 \cdot 0$ \\
\hline & Total & 14 & $100 \cdot 0$ & & 85 years of age and over & & \\
\hline & Age group 20-44 & & & 1. & Sen. mac. deg. & 37 & $48 \cdot 6$ \\
\hline 1. & Diab. ret. & 6 & $20 \cdot 0$ & 2. & Cataract & 23 & $30 \cdot 3$ \\
\hline 2. & Myopia & 6 & $20 \cdot 0$ & 3. & Glaucoma & 6 & 7.9 \\
\hline 3. & Optic atrophy & 6 & $20 \cdot 0$ & & Myopic deg. & 4 & $5 \cdot 3$ \\
\hline 4. & Uveitis & 3 & $10 \cdot 0$ & & All others & 6 & $7 \cdot 9$ \\
\hline \multirow[t]{9}{*}{5.} & Glaucoma & 2 & 6.7 & & Total & 76 & $100 \cdot 0$ \\
\hline & All others & 7 & $23 \cdot 3$ & & 65 years of age and over & & \\
\hline & Total & 30 & $100 \cdot 0$ & & Sen. mac. deg. & 196 & $38 \cdot 7$ \\
\hline & & & & & Glaucoma & 85 & $16 \cdot 8$ \\
\hline & & & & & Cataract & 63 & $12 \cdot 5$ \\
\hline & & & & & Diab. ret. & 33 & $6 \cdot 5$ \\
\hline & & & & & Myopia & 25 & 4.9 \\
\hline & & & & & All others & 104 & $20 \cdot 6$ \\
\hline & & & & & Total & 506 & $100 \cdot 0$ \\
\hline
\end{tabular}

tions in some of the age groups. When the raw data for age at onset of visual defect for males is compared with that for females, it is seen that the recorded age of onset for females was about one decade later than for males.

Although no children in the age group 0-4 were registered, subsequent registration revealed that in 23 instances (19 males and 4 females) the onset of blindness was prior to age 5 .

Data on the incidence of various primary blinding causes are presented in Fig. 3. The results are expressed in terms of the number of eyes blinded by a particular cause. A total of 1240 eyes were considered of which 714 eyes were legally blind. Fig. 3 shows the overall incidence of causes of blindess both for total registrations and the legally blind. The pattern is the same for both categories. It is clear that senile macular degeneration, accounting for about $30 \%$ of the registrations, was by far the commonest single cause of blindness in our sample.

In Table 1 the incidence of various causes of blindness among the legally blind is broken down by age of the person at onset of blindness. It is seen that retinitis pigmentosa was the main cause of blindness among the 5-19 year olds, but it appeared, if at all, only low in the ranking for all other age groups.

Diabetic retinopathy was one of the 3 first equal causes in the 20-44 year olds, the principal cause for the 45-64 years age group, the fourth most frequent cause for 65-74 and 75-84 year olds, but it did not occur at all as the blinding cause for any of the 78 eyes of the legally blind in the age group 85 years and over.

Senile macular degeneration first appeared among the 45-64 year olds and was the leading blinding cause in later years. It is interesting that of the 17 eyes blinded by senile degeneration of the macula in the 


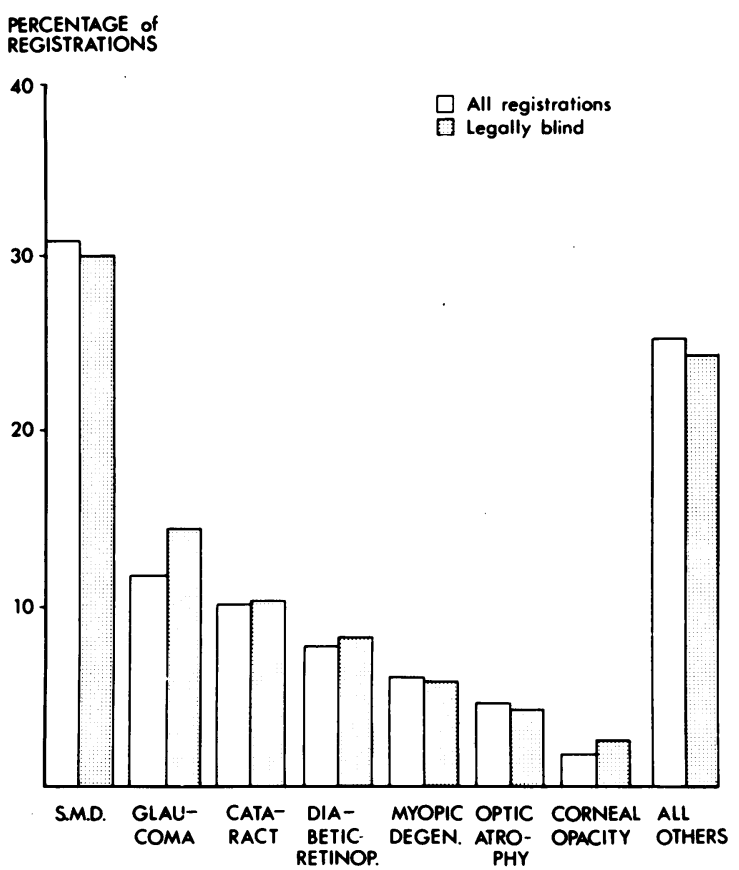

Fig. 3 Proportion of registrations attributable to various blinding causes. In 'All Others' no one cause contributes more than $2.5 \%$. Data are shown for: $\square$ all registrations; and the legally blind alone. $S M D=$ senile macular degeneration.

45-64 year olds 12 eyes were in men and 5 in women. Several differences in the pattern of blindness in the 2 sexes have already been mentioned, but others show up in the data. Table 2 shows the incidence of the different leading causes of blindness in males and females.

\section{Discussion}

The homogeneity of the population of the west of Scotland is greater than in some countries, and both environment and level of health care are uniform over this region. The moderate number of registration forms is handled by only a few staff of the Society for the Blind in Glasgow and the West of Scotland, which helps to ensure precise recording and filing of the Forms BP1, and information can be extracted easily by one person, which again assists uniform interpretation.

Although guidelines are provided to aid the the ophthalmologist in deciding whether a patient should be registered 'blind' or 'partially sighted,' some subjectivity evidently enters into the decision. To minimise this problem the registered blind who satisfied the United Kingdom criteria for legal blindness were considered here. In some previous analyses ${ }^{1}$ no distinction was drawn between age at registration and age at onset of visual defect. In the present study the age of onset was considered the more useful of these 2 alternatives.

There are problems in comparing surveys of the blind. Even when objective criteria for blindness are used, comparison with other studies is difficult, because many different definitions of blindness are in use throughout the world; the World Health Organisation accepts some 65 definitions of blindness. ${ }^{5}$ To give one example of the differences, the legally blind in the USA are those whose corrected visual acuity for distance is $20 / 200(6 / 60)$ or poorer in the better eye or with a field of vision not greater than $20^{\circ}$ at its maximum. Such differences may differentially exclude or include particular conditions, and so comparison must again be made cautiously.

However, the data from the present study shows some points which are worthy of comment. The maleto-female ratio of 2:3 among all those registered and among the legally blind is to be expected because of the longer average life span of women and the demonstrated relationship between aging and incidence of blindness. The absence of registration for those in the 0-4 age group reflects not only a reluctance of ophthalmologists to register as blind a young infant whose visual function may be difficult to assess, but also a more recently introduced policy of delaying registration in infancy.

Some $10 \%$ of blind people were found to have differing primary causes of blindness in their 2 eyes, but these conditions cover the whole range. Thus the percentage affected by a particular cause is about the same whether eyes or people are considered.

Table 2 Common causes of blindness in males and females, west of Scotland, 1980

\begin{tabular}{|c|c|c|c|c|c|}
\hline Males & Eyes & $\%$ & Females & Eyes & $\%$ \\
\hline 1. Senile macular degeneration & 62 & $22 \cdot 5$ & 1. Senile macular degeneration & 151 & $34 \cdot 5$ \\
\hline 2. Glaucoma & 55 & $19 \cdot 9$ & 2. Cataract & 58 & $13 \cdot 2$ \\
\hline 3. Optic nerve atrophy & 24 & $8 \cdot 7$ & 3. Diabetic retinopathy & 51 & $11 \cdot 6$ \\
\hline 4. Cataract & 16 & $5 \cdot 8$ & 4. Glaucoma & 49 & $11 \cdot 2$ \\
\hline 5. Myopic degeneration & 11 & $4 \cdot 0$ & 5. Myopic degeneration & 32 & $7 \cdot 3$ \\
\hline All other & 108 & $39 \cdot 1$ & All other & 97 & $22 \cdot 2$ \\
\hline Total & 276 & $100 \cdot 0$ & Total & 438 & $100 \cdot 0$ \\
\hline
\end{tabular}


Table 3 Comparison of the important causes of blindness in some countries

\begin{tabular}{|c|c|c|c|c|c|}
\hline Country & Ist cause & 2nd cause & $3 r d$ cause & 4th cause & Sth cause \\
\hline Scotland & $\begin{array}{l}\text { Senile macular } \\
\text { degeneration }\end{array}$ & Glaucoma & Cataract & $\begin{array}{l}\text { Diabetic } \\
\text { retinopathy }\end{array}$ & Myopia \\
\hline $\begin{array}{l}\text { England and } \\
\text { Wales }\end{array}$ & $\begin{array}{l}\text { Senile macular } \\
\text { degeneration }\end{array}$ & Cataract & Glaucoma & Myopia & Diabetic retinopathy \\
\hline USA & Glaucoma & $\begin{array}{l}\text { Senile macular } \\
\text { degeneration }\end{array}$ & Cataract & Optic nerve atrophy & Diabetic retinopathy \\
\hline Canada & $\begin{array}{l}\text { Senile macular } \\
\text { degeneration }\end{array}$ & $\begin{array}{l}\text { Diabetic } \\
\text { retinopathy }\end{array}$ & Glaucoma & Optic nerve atrophy & Cataract \\
\hline Sweden & $\begin{array}{l}\text { Tapetoretinal } \\
\text { degeneration of } \\
\text { genetic origin }\end{array}$ & $\begin{array}{l}\text { Diabetic } \\
\text { retinopathy }\end{array}$ & Optic nerve atrophy & Uveitis & Myopia \\
\hline India & Cataract & Glaucoma & Staphyloma & Optic nerve atrophy & Anophthalmos \\
\hline
\end{tabular}

If the figures for cataract and glaucoma are combined, one finds that about a quarter of all legal blindness or severe visual handicap results from these 2 conditions, the effects of which are largely treatable or preventable respectively. It is encouraging to note that the figure of $10 \%$ of the registrations attributable to senile cataract signifies an improvement since the time of Sorsby's survey, ${ }^{1}$ when $23 \%$ of registrations were for this reason. The percentage for glaucoma has shown little change (14.6\% for our data and $13 \%$ in Sorsby's results).

It has been suggested that a tight control of the diabetic state together with early treatment of proliferative retinopathy with laser or xenon arc photocoagulation might prevent $60 \%$ of blindness from diabetes. ${ }^{6}$ If this was achieved, some $8 \%$ of the blind registrations in the west of Scotland would be eliminated.

Thus about $30 \%$ of current registrations might be prevented by rigorous application of current treatment techniques for cataract, glaucoma, and diabetic retinopathy. But a proportion of those whose sight was saved would subsequently lose vision from an as yet untreatable cause of blindness such as senile macular degeneration.

It has already been noted that diabetes is the commonest systemic disorder causing blindness, yet it does not figure as a major cause of blindness among the 85 year olds. This evidently reflects the shorter life expectancy of diabetics, and in addition many are blinded while still relatively young and so do not contribute to registrations in the older age groups.

Cataract is a more important cause of blindness for women than for men, again reflecting the longer life span for females. Diabetic retinopathy ranks as the third cause of blindness for females, yet it does not show among the first 5 conditions for men. This again might be a phenomenon related to life expectancy (Table 2).

COMPARISON WITH OTHER COUNTRIES

As remarked earlier, there are many obstacles to comparing the results of surveys such as this. With these reservations in mind, the pattern of incidence of common causes of blindness is shown for several countries in Table 3. It is apparent that at least for developed countries ${ }^{1-37}$ the same causes tend to appear among the leading 5, although the order changes.

As an example of the problems of detailed comparison, one might speculate that the interchange of the order of glaucoma and senile macular degeneration for the USA in comparison with the UK might be due to the different visual field criteria for blindness used in each. There is not sufficient information about visual fields on the Form BP1 to analyse blind population data for the west of Scotland by the USA criteria.

The contrast between India (Venkataswamy 1981, personal communication) and the other nations is marked, but it is much what the differing social and medical care conditions would lead one to expect.

We wish to thank Mr D. Anderson and Mr S. J. Magill of the Society for the Blind in Glasgow and the West of Scotland and their staff for their help and co-operation during the conduct of this study. Our thanks are due also to Miss $O$. M. Rankin and Mrs J. Murray for secretarial services.

\section{References}

1 Sorsby S. The incidence and causes of blindness in England and Wales. Rep Health Soc Subj (Lond) 1966; 14.

2 Lindstedt E. Causes of blindness in Sweden. Acta Ophthalmol (Kbh) 1969; 104 (suppl): 22-74.

3 National Society to Prevent Blindness. Vision problems in the US. New York: NSPB, 1980.

4 Registrar General, Scotland. Annual estimate of the population of Scotland, 1980. Edinburgh, HMSO: 1981.

5 Blindness. World Health Organisation Epidemiological and Vital Statistics Report 1966; 19: 433-512.

6 Kohner EM. The solution of the problem. Trans Ophthalmol Soc UK 1978; 98: 299-302.

7 Canadian National Institute for the Blind. Statistical studies on the blind population of Canada registered with CNIB, 1979. Toronto: CNIB, 1981 